\title{
Development of a Nursing Practice Rating Scale for Hospitalized Pregnant Women with Threatened Preterm Labor
}

\section{Hiromi Yamamoto ${ }^{1 *}$ and Miyako Oike ${ }^{2}$}

${ }^{1}$ Department of Nursing, Faculty of Fukuoka Medical Technology Teikyo University, 6-22 Misaki-machi, Omuta-shi, Fukuoka 836-8505, Japan ${ }^{2}$ Department of Nursing, Faculty of Fukuoka Nursing International University of Health and Welfare, Fukuoka, Japan

\section{Abstract}

Objective: This study aims to develop and validate the Nursing Practice Rating Scale for Hospitalized Pregnant Women with Threatened Preterm Labor (NPRS-HTPL) instrument for clinical Japanese nurses. Design: Cross-sectional study.

Setting: General hospitals in Japan with perinatal medical centers.

Participants: This study collected a total of 744 nurse participants who experienced caring for pregnant women hospitalized with threatened preterm labor from 88hospitals.

Methods: The items in the Nursing Practice Rating Scale for Hospitalized Pregnant Women with Threatened Preterm Labor (NPRS-HTPL) were extracted from previous research. The reliability and validity of the newly developed scale were assessed through the split-half method, internal consistency, criterion-related validity, and construct validity. The construct validity was examined by conducting a factor analysis and using the structural equation modeling (SEM).

Results: The final NPRS-HTPL contained 45 items, and factor analysis identified five factors: Care That Enhances Self-care Ability (13 items), Care That Changes Depending on the Situation ( 7 items), Care That Respects the Wishes of Pregnant Women With Threatened Preterm Labor (9 items), Care Related to Information to Predict the Future Lives of Pregnant Women With Threatened Preterm Labor (8 items), and Practical Care for Continued Pregnancy ( 8 items). Cronbach's alpha coefficient of reliability for the five factors ranged from 0.85 to 0.92 and was 0.96 for the 45 items. Confirmatory factor analysis was performed, using SEM. Analysis revealed a goodness-of-fit index (GFI) of 0.808 and the root mean square error of approximation was 0.06 , which means an acceptable goodness of fit for this model.

Conclusion: The reliability of the NPRS-HTPL was supported. The scale may be a useful tool with which to evaluate nursing practice to support pregnant women with threatened preterm labor while they are in hospital.

\section{Introduction}

Threatened preterm labor (TPL) is defined as: a high risk of preterm birth; regular uterine contractions; progression in the Bishop score; and symptoms such as lower abdominal pain, vaginal bleeding, and amniotic membrane rupture between 22 and 37 weeks gestation [1]. In Japan, hospitalization is the standard practice to treat TPL. The purpose of hospitalization is to achieve fetal growth and maturation by extending the gestational period as long as possible. Decreases in neonatal morbidity and mortality can be expected with this practice, and a consequent decrease in medical costs has also been shown [2]. When there is evidence of TPL, such as uterine contractions and cervical dilation, the treatment strategy is determined based on Baumgarten's Tocolysis Index [3]. A score of 3 or more indicates that the woman's care should be managed with hospitalization. Hospitalized women can rest and receive treatment with uterine contraction inhibitors and other treatment to prevent uterine contractions caused by bacterial infection and inflammation [4].

The current trend in Japan is to identify TPL and begin treatment at an early stage. Inflammation has become widely accepted as a cause of preterm birth, and its identification and suppression has become a critical part of the treatment strategy [5]. The rate of preterm birth in Japan is ranked as one of the lowest among developed countries, at approximately 5\% [6], and it is assumed that this is a result of hospitalization with combined drug and rest therapy. Drug therapy involves the use of a tocolytic agent orally or by intravenous drip, and rest therapy involves relaxation of uterine contractions and restriction investigated [7]. original author and source are credited.

\section{Publication History:}

Received: November 06, 2017 Accepted: December 27, 2017 Published: December 29, 2017

\section{Keywords:}

Pregnant women, Threatened preterm labor, Hospitalization, Scale development, Nursing practice rating scale been scientifically proven to be an effective treatment for preterm labor. The drugs that have been approved for drug therapy differ from country to country, so the benefits of prolonging gestation and the risks of drug-related side effects when using these drugs need to be

Rest therapy is a medical intervention for TPL that arose from a lack of other feasible therapies [8]. The American College of Obstetricians and Gynecologists [9] indicated that there is insufficient evidence for bed rest as a means to prevent premature labor. Other therapies for preventing premature labor include short- and long-term tocolysis therapy (STTT and LTTT). STTT is the use of a uterine contraction inhibitor that has been used in Europe and the United States and has been reported to prolong pregnancy by approximately 72 hours [7]. In Japan, LTTT, which involves the use of a tocolytic agent, prioritizes the continuation of pregnancy for as long as possible and is combined with bed rest in hospital to delay preterm birth.

"Corresponding Author: Hiromi Yamamoto, Department of Nursing, Faculty of Fukuoka Medical Technology Teikyo University, 6-22 Misaki-machi, Omuta-shi, Fukuoka 836-8505, Japan; E-mail: h-yamamoto@fmt.teikyo-u.ac.jp

Citation: Yamamoto H, Oike M (2017) Development of a Nursing Practice Rating Scale for Hospitalized Pregnant Women with Threatened Preterm Labor. Int J Nurs Clin Pract 4: 265. doi: https://doi.org/10.15344/2394-4978/2017/265

Copyright: (C) 2017 Yamamoto et al. This is an open-access article distributed under the terms of the Creative Commons Attribution License, which permits unrestricted use, distribution, and reproduction in any medium, provided the 
Tanaka et al. [1] found that the rate of preterm births at or less than 37 weeks' gestation in Japan was about half that of the United States. However, there are several problems with LTTT and long-term rest as inpatient treatments for pregnant women with TPL. For example, longterm hospitalization has adverse physical effects, such as decreased heart, muscle, and skeletal function, and it has been reported to cause insomnia, emotional instability, and decreased cognitive performance [10]. Being separated from their families also caused loneliness for pregnant women, along with other psychological and social adverse effects [11]. Hospitalized pregnant women with TPL have been found to be anxious about their pregnancy, although generally happy [12]. An earlier study, however, found that hospitalization could reduce anxiety in these women as they became able to manage their preterm symptoms by themselves [13]. Hospitalized pregnant women with TPL also had positive experiences in hospital, such as a sense of security and readiness for motherhood [14], and relaxation using aromatic baths and meetings with other pregnant women were useful to reduce anxiety or stress $[15,16]$. A maternity diary was useful in supporting self-care in hospitalized pregnant women with TPL [17]. These findings all suggest the importance of nursing interventions for hospitalized pregnant woman with TPL.

Nurses are responsible for providing high-quality care for hospitalized pregnant women with TPL. Although research in this area has been progressing internationally since 1997, the causes of and ideal treatments for TPL have yet to be established. Researchers have not fully investigated care practices that promote the gestational period as a time for self-care and preparation for becoming a mother. Additionally, although problems such as anxiety and stress associated with signs of preterm birth have been delineated, specific care practices to address anxiety and stress have yet to be verified.

In areas such as cancer nursing, care practice scales have been developed, shared, and used for evaluation $[18,19]$. Measurement of the care they provide clarifies care problems and challenges and can allow nurses to objectively reflect on their practice through self-evaluation [19]. Such measurement is also thought to enhance consistent nursing practice because nurses share information with each other [20]. In this study, nursing practice was defined as care targeted at women with TPL who were hospitalized for at least 1 week on bed rest and who received long-term tocolysis therapy (LTTT) and support with daily activities during their hospital stay. This study aims to develop and validate the Nursing Practice Rating Scale for Hospitalized Pregnant Women with Threatened Preterm Labor (NPRS-HTPL) instrument for clinical Japanese nurses.

\section{Method}

\section{Setting and participants}

A survey (Survey 1) was conducted in general hospitals in Japan with facilities for perinatal care, including advanced neonatal care and care for high-risk pregnancies, such as complicated pregnancies, severe pre-eclampsia, TPL, and fetal abnormalities. These hospitals handle between 200 and 1,000 births per year and have around 20 midwives and nurses on their staff. A total of 291 units were randomly chosen from the national hospital directory of the 2003-2004 hospital guidebook (Medical Facility Policy Study Group). To eliminate regional bias, researchers checked to ensure that the sample included hospitals from every prefecture. A letter asking for their cooperation in this study and a consent form were sent to the head nurses of these hospitals. Head nurses who agreed to cooperate were asked to provide details of the number of nurses potentially eligible for the study at their facility. A total of 1,676 nurses from 88 hospitals ultimately gave their consent to participate. The survey period was from March 6th to May 23rd, 2015.

A second survey (Survey 2) was conducted among 133 nurses who participated in the first survey and agreed to cooperate with both primary and secondary investigations. The survey period was from May 8th to June 8th, 2015.

\section{Procedure}

\section{Survey 1}

The questionnaire contained questions on demographic characteristics, the Nursing Practice Rating Scale for Hospitalized Pregnant Women with Threatened Preterm Labor (NPRS-HTPL), the Autonomy Scale of Nurses (ASN) [21], and the Quality of Nursing Care Questionnaire: For Nurses (QNCQ) [22]. Answers to the NPRSHTPL were given on a five-point Likert-type scale from " 1 - Not done at all" to " 5 - Done very well". Respondents were asked to circle the answer that was most applicable. The total score and subscale scores were summed, and a higher score indicated a higher care level.

The reliability and validity of the ASN and QNCQ have been evaluated. The ASN is a five-factor scale that measures nurse proficiency and autonomy, with nursing activity situations in nursing settings broadly divided into the three domains of cognition, judgment, and practice [21]. Cronbach's alpha ranged from 0.93 to 0.79 for each factor. The scale has 43 questions rated on a five-point Likert-type scale from " 1 - Applies considerably" to " 5 - Does not apply at all", and respondents circled the number that applied most. The ASN was used because it includes concepts underlying the care measured by the NPRS-HTPL. It therefore ensured that the NPRSHTPL accurately measures the concepts involving in providing nursing care. The QNCQ, used to evaluate the quality of nursing care in clinical fields, includes five factors: Care Associated with Treatment and/or Testing and Interpersonal Relationships; Care Related to Environmental Adjustments and Rest; Care to Alleviate Patient Anxiety; Care Related to Hygiene and Excretion; and Care Related to Activity and Diet [22]. Cronbach's alpha was 0.96 overall and ranged from 0.76 to 0.79 for the five factors. The scale has 39 questions that are rated on a four-point Likert-type scale from " 1 - Does not apply" to "4 - Applies strongly", and respondents circled the number that applied most. The QNCQ was used in this study because it covers the concepts related to the quality of nursing practice, and could therefore be used to check that the NPRS-HTPL assessed these ideas accurately.

\section{Survey 2}

A re-test was used to examine scale stability, an aspect of reliability. The same participants were asked to take the same survey a second time after a period of about 1 month.

\section{Data analysis}

Analyses of Survey 1 were conducted under the supervision of an expert in statistics and included item analysis, factor analysis, and examination of validity and reliability. To examine validity, the relationships between the NPRS-HTPL and the ASN, and between 
Citation: Yamamoto H, Oike M (2017) Development of a Nursing Practice Rating Scale for Hospitalized Pregnant Women with Threatened Preterm Labor. Int J Nurs Clin Pract 4: 265. doi: https://doi.org/10.15344/2394-4978/2017/265

Page 2 of 8

the NPRS-HTPL and the QNCQ were analyzed using Pearson's correlation coefficient. The factor scores of the NPRS-HTPL and participants' years of clinical experience were examined using one -way ANOVA and the Kruskal-Wallis test. The construct validity was tested using factor analysis and structural equation modeling (SEM). To examine reliability, Cronbach's alpha coefficients were calculated for the overall scale and for each item, and these coefficients were examined using the split-half method.

For Survey 2, Spearman's correlation coefficients between the scores of the two measurements were calculated and used as the confidence coefficient.

\section{Ethical approval}

The institutional ethics board approved this study following a review of the participants (pregnant women, nurses, and midwives), study methods, and ethical.

\section{Results}

\section{Survey 1}

The characteristics of the study participants are summarized in Table 1 . In total, 744 nurses returned the Survey 1 questionnaire (response rate: 44\%), and 699 of them gave valid responses (valid response rate: $42 \%$ ). All participants were women, with a mean age of 35.1 (standard deviation [SD] 9.5) years and mean experience with pregnant women with TPL of 8.8 (SD 7.6) years. The most common job position among participants was staff (599 individuals, 86\%), and the most common job category was midwife (620 individuals, $89 \%$ ).

The 63 question items of the NPRS-HTPL were examined for ceiling and floor effects. A ceiling effect was seen in five items and a floor effect in one. All six of these items $(7,11,36,51,52$, and 53) were removed. The inter-item correlation with 12 pairs was at least $r=$ 0.7 . As a result, 11 further items were removed. Item-Total correlation analysis produced correlation coefficients ranging from 0.34 to 0.74 , indicating internal consistency, and no items were removed as a result of this. In the Good-Poor analysis, a significant difference $(\mathrm{p}<0.001)$ was seen in all means between all items in the high $(25 \%)$ and low score groups (25\%). Distinctiveness was therefore confirmed, and no items were removed.

The 46 remaining items were subjected to principal component analysis, which revealed principal component factor loadings ranging from 0.43 to 0.75 . An exploratory factor analysis using the principal factor method and promax rotation was then used, with a factor loading of at least 0.4 as the adoption criterion. One item (31) had a loading of less than 0.4 and was removed. Items were organized further through repeated confirmation of commonality and changes in alpha coefficients. The final NPRS-HTPL consisted of 45 items across five factors (Table 2).

Cronbach's alpha coefficient for the total NPRS-HTPL was 0.96, with coefficients ranging from 0.85 to 0.92 for the five factors (see Table 3). Examination using the split-half method revealed an odd number mean of 81.34 (SD 12.66), an even number mean of 84.49 (SD 12.69), and an extremely strong positive correlation, with a correlation coefficient of $0.98(\mathrm{p}<0.01)$ by the split-half method.

\begin{tabular}{|c|c|c|}
\hline Variable & $\mathrm{n}$ & $\%$ \\
\hline \multicolumn{3}{|l|}{ Age, years } \\
\hline$\leq 30$ & 303 & 43.3 \\
\hline $31-40$ & 169 & 24.2 \\
\hline$\geq 41$ & 227 & 32.5 \\
\hline \multicolumn{3}{|l|}{ Occupation } \\
\hline Nurse & 620 & 88.7 \\
\hline Midwife & 79 & 11.3 \\
\hline \multicolumn{3}{|l|}{ Job title } \\
\hline Chief nurse & 14 & 2.0 \\
\hline Deputy chief nurse & 78 & 11.2 \\
\hline Staff & 599 & 85.7 \\
\hline Other & 8 & 1.1 \\
\hline \multicolumn{3}{|l|}{ Educational level } \\
\hline Postgraduate school & 31 & 4.4 \\
\hline University & 228 & 32.6 \\
\hline Junior college & 19 & 2.7 \\
\hline Vocational school & 421 & 60.2 \\
\hline \multicolumn{3}{|c|}{ Years of clinical experience of care for pregnant women with TPL } \\
\hline $1-5$ & 322 & 46.1 \\
\hline $6-10$ & 164 & 23.5 \\
\hline $11-20$ & 155 & 22.2 \\
\hline$\geq 21$ & 58 & 8.3 \\
\hline \multicolumn{3}{|c|}{ Frequency of care for pregnant women with TPL } \\
\hline Daily & 393 & 56.2 \\
\hline At least once per week & 215 & 30.8 \\
\hline At least once every two weeks & 21 & 3.0 \\
\hline At least once per month & 27 & 3.8 \\
\hline At least once per year & 17 & 2.4 \\
\hline Almost no care in this past year & 20 & 2.9 \\
\hline Other & 6 & 0.9 \\
\hline
\end{tabular}

There was a correlation range of 0.50 between the NPRS-HTPL and the ASN. Correlations ranging from 0.03 to 0.50 were seen between the NPRS-HTPL and each ability. There was also a positive correlation of 0.60 between the QNCQ, evaluating the quality of nursing care, and the NPRS-HTPL. Significant correlations ranging from 0.34 to 0.56 were seen among all factors of the NPRS-HTPL and the QNCQ (Table 3).

A covariance structure analysis was used to examine whether data based on the results of the exploratory factor analysis were consistent. Exploratory factor analysis resulted in five factors. Confirmatory factor analysis was performed, using SEM. Analysis revealed a goodness-of-fit index (GFI) of 0.808 , an adjusted GFI (AGFI) of 0.789 , the comparative fit index was 0.87 and the root mean square error of approximation was 0.06 , which means an acceptable goodness of fit for this model. The goodness-of-fit indices of each part of the model all had coefficients of at least 0.5 , confirming their significance $(\mathrm{p}<$ 0.001 ). These findings indicated that the hypothetical model fitted well. The reliability of the NPRS-HTPL was supported. This scale useful tool with which to evaluate nursing practice. 
Citation: Yamamoto H, Oike M (2017) Development of a Nursing Practice Rating Scale for Hospitalized Pregnant Women with Threatened Preterm Labor. Int J Nurs Clin Pract 4: 265. doi: https://doi.org/10.15344/2394-4978/2017/265

Page 4 of 8

\begin{tabular}{|c|c|c|c|c|c|}
\hline \multirow[t]{2}{*}{ Factor name (Cronbach's alpha for the overall scale $=0.966)$} & \multicolumn{5}{|c|}{ Factor loading } \\
\hline & Factor 1 & Factor 2 & Factor 3 & Factor 4 & Factor 5 \\
\hline \multicolumn{6}{|l|}{ Factor 1 Care that Enhances Self-Care Ability $(\alpha=0.914)$} \\
\hline $\begin{array}{l}23 \text { Explain psychological characteristics during pregnancy to pregnant women with } \\
\text { threatened premature labor and their families }\end{array}$ & .752 & -.054 & .219 & -.136 & -.013 \\
\hline 21 Teach relaxation methods designed to relieve mental and physical tension & .721 & .000 & .204 & -.141 & -.034 \\
\hline $\begin{array}{l}30 \text { Provide an environment in which pregnant women with threatened premature labor can } \\
\text { convey to their family the feelings they have towards their family (feelings of apology, being a } \\
\text { burden, sense of alienation, etc.) }\end{array}$ & .672 & -.057 & .100 & .034 & -.005 \\
\hline 26 Understand the feelings of the partner & .642 & -.080 & .112 & -.025 & -.036 \\
\hline $\begin{array}{l}29 \text { Provide settings for interactions with others (roommates, other pregnant women with } \\
\text { threatened premature labor, etc.) }\end{array}$ & .596 & .066 & .095 & .059 & -.007 \\
\hline 46 Knowing how decision-making was demonstrated until now & .575 & .054 & -.090 & .248 & .037 \\
\hline 38 Actively provide opportunities for the partner to engage with the fetus & .571 & .022 & -.205 & .302 & .015 \\
\hline 48 Allow women to realize their own strength and ability & .558 & .043 & -.070 & .334 & -.060 \\
\hline 3 Implement methods of preventing weakness of both lower limbs & .523 & .035 & -.164 & -.169 & .308 \\
\hline $\begin{array}{l}44 \text { Discuss hospital life so that thinking about how to live each current day does not become } \\
\text { stressful }\end{array}$ & .515 & .133 & -.025 & .185 & .027 \\
\hline $\begin{array}{l}35 \text { Coordinate times, places, and content so that women can practice after antepartum } \\
\text { education }\end{array}$ & .508 & .044 & -.345 & .414 & .003 \\
\hline $\begin{array}{l}28 \text { Provide information on social resources that women can use for problems related to } \\
\text { hospital life }\end{array}$ & .491 & .001 & .093 & .076 & .087 \\
\hline $\begin{array}{l}20 \text { Make suggestions to provide a change of pace to women, such as reading, music, walking } \\
\text { (wheelchair) }\end{array}$ & .485 & .016 & .319 & -.060 & -.048 \\
\hline \multicolumn{6}{|l|}{ Factor 2 Care That Changes Depending on the Situation $(\alpha=0.902)$} \\
\hline $\begin{array}{l}56 \text { Allow plenty of time when providing pregnant women with threatened premature labor } \\
\text { with treatment and care }\end{array}$ & .093 & .842 & -.114 & -.057 & -.023 \\
\hline 60 Address complaints promptly & -.067 & .784 & -.018 & .060 & .000 \\
\hline $\begin{array}{l}63 \text { Interact with pregnant women with threatened premature labor with enthusiasm in } \\
\text { hospital life and treatment }\end{array}$ & .070 & .756 & .106 & -.102 & .007 \\
\hline 55 Pay attention to the tone, tempo, volume, and intonation of women's voices & -.106 & .748 & .068 & .049 & -.021 \\
\hline $\begin{array}{l}62 \text { Perform tests and treatment taking into account the circumstances of pregnant women } \\
\text { with threatened premature labor }\end{array}$ & .004 & .734 & .019 & -.013 & .025 \\
\hline 61 Explain results of blood tests, other tests, and prenatal checkups at each occasion & .043 & .600 & -.021 & -.003 & .104 \\
\hline 57 Act as a confidant & .137 & .588 & .207 & -.021 & -.036 \\
\hline \multicolumn{6}{|l|}{ Factor 3 Care That Respects the Wishes of Pregnant Women With TPL $(\alpha=0.920)$} \\
\hline 18 Think about care that can help women maintain and continue wishing for a safe delivery & .262 & .016 & .818 & .027 & -.059 \\
\hline $\begin{array}{l}16 \text { Understand that pregnant women with threatened premature labor and their fetuses are } \\
\text { doing their best together }\end{array}$ & .230 & .049 & .735 & .093 & .054 \\
\hline $\begin{array}{l}15 \text { Understand the feelings of the pregnant women with threatened premature labor if their } \\
\text { body will hold up as a result of hospitalization and treatment }\end{array}$ & -.146 & .020 & .690 & -.025 & .041 \\
\hline $\begin{array}{l}14 \text { Listen not only to the content of women's conversations, but also the underlying messages } \\
\text { and emotions }\end{array}$ & .084 & .115 & .637 & -.084 & .036 \\
\hline $\begin{array}{l}17 \text { Continuously talk with pregnant women with threatened premature labor so that they can } \\
\text { discover the value in becoming pregnant }\end{array}$ & .123 & -.017 & .636 & -.079 & .032 \\
\hline $\begin{array}{l}12 \text { Understand how women accept their present situation (hospitalization, course of } \\
\text { pregnancy, treatment) }\end{array}$ & .019 & -.026 & .599 & .165 & .126 \\
\hline 24 Present an attitude of respect for women's self-determination & -.010 & .046 & .571 & .112 & .045 \\
\hline $\begin{array}{l}22 \text { Teach pregnant women with threatened premature labor how to understand and prevent } \\
\text { living behaviors that lead to premature labor }\end{array}$ & .099 & -.039 & .530 & .267 & -.012 \\
\hline 25 Explain the need for support from partners and families & .097 & -.041 & .394 & .168 & .010 \\
\hline
\end{tabular}


Citation: Yamamoto H, Oike M (2017) Development of a Nursing Practice Rating Scale for Hospitalized Pregnant Women with Threatened Preterm Labor. Int J Nurs Clin Pract 4: 265. doi: https://doi.org/10.15344/2394-4978/2017/265

Page 5 of 8

\begin{tabular}{|c|c|c|c|c|c|}
\hline $\begin{array}{l}32 \text { Evaluate women's level of knowledge of childbirth and childcare and their level of } \\
\text { understanding of the content }\end{array}$ & .079 & -.004 & .077 & .685 & -.009 \\
\hline $\begin{array}{l}37 \text { Think of ways in which pregnant women with threatened premature labor and their } \\
\text { families can prepare for childbirth if they are unprepared for delivery }\end{array}$ & .134 & .009 & -.018 & .630 & -.009 \\
\hline 39 Explain breastfeeding & .054 & -.187 & .067 & .622 & .125 \\
\hline 47 Provide information capable of predicting childbirth and childcare & .214 & -.030 & .043 & .571 & .011 \\
\hline $\begin{array}{l}50 \text { Explain the status of the mother and fetus, symptoms of threatened premature labor, } \\
\text { and the course of pregnancy to pregnant women with threatened premature labor and their } \\
\text { families until they understand }\end{array}$ & -.089 & .128 & .207 & .528 & .035 \\
\hline 49 Check if the physician's explanation is satisfactory, and if not, convey this to the physician & -.307 & .156 & .340 & .518 & .025 \\
\hline $\begin{array}{l}34 \text { Understand the feelings of pregnant women with threatened premature labor and their } \\
\text { partners regarding childbirth and childcare }\end{array}$ & .375 & .051 & .067 & .441 & -.116 \\
\hline 40 Offer words that inspire women to set goals to continue pregnancy & -.087 & .131 & .313 & .437 & .075 \\
\hline \multicolumn{6}{|l|}{ Factor 5 Practical Care for Continued Pregnancy $(\alpha=0.848)$} \\
\hline $\begin{array}{l}1 \text { Implement methods that can alleviate the side effects of drugs (palpitations, hot flushes, } \\
\text { penetration pain, etc.) }\end{array}$ & -.127 & -.008 & .009 & .088 & .736 \\
\hline 2 Implement methods to relieve low back pain and other pain from bed rest & .138 & .014 & -.086 & -.012 & .647 \\
\hline 5 Teach women positions that can alleviate abdominal strain & .068 & -.062 & .034 & .096 & .602 \\
\hline 6 Contrive ways to make it easier for pregnant women with TPL to move independently & .122 & .063 & .058 & -.065 & .528 \\
\hline 9 Plan excretion control and facilitate excretion & -.154 & .072 & .160 & .103 & .508 \\
\hline 8 Check that food is suitable for anemia or women's appetite & .091 & .108 & .026 & -.027 & .446 \\
\hline 10 Teach methods of coping with insomnia or poor sleep & .332 & .011 & .092 & -.122 & .440 \\
\hline 4 Explain the advantages and disadvantages of bed rest & .104 & -.094 & .038 & .184 & .430 \\
\hline Cumulative contribution ratio (\%) & 40.370 & 45.011 & 47.876 & 50.497 & 52.512 \\
\hline Factor 2 & .559 & & & & \\
\hline Factor 3 & .611 & .709 & & & \\
\hline Factor 4 & .601 & .603 & .654 & & \\
\hline Factor 5 & .601 & .550 & .658 & .567 & \\
\hline Note. $\mathrm{N}=613 . \mathrm{TPL}=$ threatened preterm labor. & & & & & \\
\hline
\end{tabular}

Table 2: The comparison results between technological competency of caring in nursing recognition and its practical situation.

\begin{tabular}{|c|c|c|c|c|c|c|}
\hline & \multicolumn{6}{|c|}{$\begin{array}{c}\text { Nursing Practice Rating Scale for Hospitalized Pregnant Women } \\
\text { with Threatened Premature Labor }\end{array}$} \\
\hline & Total score & Factor 1 & Factor 2 & Factor 3 & Factor 4 & Factor 5 \\
\hline Autonomy Scale of Nurses $(n=613)$ total score & $.540^{* *}$ & $.511^{\star *}$ & $.445^{\star *}$ & $.477^{\star *}$ & $.457^{\star *}$ & $.422^{* *}$ \\
\hline 1. Cognitive ability & $.559^{* *}$ & $.499^{*}$ & $.462^{* *}$ & $.519^{* *}$ & $.472^{* *}$ & $.427^{* *}$ \\
\hline 2. Practical ability & $.474^{* *}$ & $.437^{* *}$ & $.413^{* *}$ & $.416^{* *}$ & $.396^{* *}$ & $.380^{* *}$ \\
\hline 3. Specific judgment ability & $.479^{* *}$ & $.426^{* *}$ & $.397^{* *}$ & $.430^{* *}$ & $.430^{* *}$ & $.381^{* *}$ \\
\hline 4. Abstract judgment ability & $.492^{* *}$ & $.484^{* *}$ & $.391^{* *}$ & $.421^{* *}$ & $.437^{* *}$ & $.385^{* *}$ \\
\hline 5. Autonomous judgment ability & $-.140^{* *}$ & -.033 & $-.162^{* *}$ & $-.163^{* *}$ & $-.163^{* *}$ & $-.119^{* *}$ \\
\hline Scale to Evaluate the Quality of Nursing Care $(n=613)$ total score & $.600^{* *}$ & $.470^{* *}$ & $.556^{* *}$ & $.559^{* *}$ & $.508^{* *}$ & $.461^{* *}$ \\
\hline 1. Care associated with treatment and testing and interpersonal relationships & $.540^{* *}$ & $.444^{* *}$ & $.503^{* *}$ & $.494^{* *}$ & $.462^{* *}$ & $.425^{* *}$ \\
\hline 2. Care related to environmental adjustments and rest & $.562^{* *}$ & $.436^{* *}$ & $.510^{* *}$ & $.518^{* *}$ & $.477^{* *}$ & $.424^{* *}$ \\
\hline 3. Care to alleviate patient anxiety & $.507^{* *}$ & $.375^{* *}$ & $.497^{* *}$ & $.503^{* *}$ & $.427^{* *}$ & $.344^{* *}$ \\
\hline 4. Care related to hygiene and excretion & $.538^{* *}$ & $.396^{* *}$ & $.488^{* *}$ & $.505^{* *}$ & $.466^{* *}$ & $.423^{* *}$ \\
\hline 5. Care related to activity and diet & $.522^{* *}$ & $.408^{* *}$ & $.485^{* *}$ & $.487^{* *}$ & $.408^{* *}$ & $.415^{* *}$ \\
\hline
\end{tabular}

Table 3: Correlation of the Autonomy Scale of Nurses (ASN) and the Quality of Nursing Care Questionnaire: For Nurses (QNCQ) to the Nursing Practice Rating Scale for Hospitalized Pregnant Women with TPL (NPRS-HTPL).

Note. $\mathrm{N}=613$. TPL $=$ threatened preterm labor. ${ }^{* *} \mathrm{p}<.01$. 
Citation: Yamamoto H, Oike M (2017) Development of a Nursing Practice Rating Scale for Hospitalized Pregnant Women with Threatened Preterm Labor. Int J Nurs Clin Pract 4: 265. doi: https://doi.org/10.15344/2394-4978/2017/265

Page 6 of 8

A covariance structure analysis was used to examine whether data based on the results of the exploratory factor analysis were consistent. Exploratory factor analysis resulted in five factors. Confirmatory factor analysis was performed, using SEM. Analysis revealed a goodness-of-fit index (GFI) of 0.808, an adjusted GFI (AGFI) of 0.789, the comparative fit index was 0.87 and the root mean square error of approximation was 0.06 , which means an acceptable goodness of fit for this model. The goodness-of-fit indices of each part of the model all had coefficients of at least 0.5 , confirming their significance ( $\mathrm{p}<$ $0.001)$. These findings indicated that the hypothetical model fitted well. The reliability of the NPRS-HTPL was supported. This scale useful tool with which to evaluate nursing practice.

Participants were divided into four groups by their years of clinical experience with pregnant women with TPL (Table 4). There was a significant difference among the groups for the total score and all subordinate factors.

\section{Survey 2}

A total of 133 participants agreed to participate in the re-test. Responses were recovered from 39 of them (29\%), and the number of valid responses was $35(26 \%)$. The test-retest reliability coefficient was $r=0.83(p<0.01)$ for the total score of the NPRS-TPL, $0.66(p<0.01)$ for Factor 1, $0.63(\mathrm{p}<0.01)$ for Factor 2, $0.43(\mathrm{p}<0.05)$ for Factor 3, $0.74(\mathrm{p}<0.01)$ for Factor 4 , and $0.76(\mathrm{p}<0.01)$ for Factor 5.

\section{Discussion}

This study developed the NPRS-HTPL, a scale capable of evaluating the level of care provided by nurses to pregnant women with TPL. It examined the reliability and validity of this scale as a means of promoting the provision of consistent, high-quality care for pregnant women with TPL.

\section{Reliability}

Reliability was demonstrated by internal consistency, with values exceeding 0.07 [23], the recommended level. Examination of reliability using the split-half method also confirmed that internal consistency was sufficiently supported. The correlation coefficient of measured values was obtained from two surveys completed by the same participants. It also showed that both the NPRS-HTPL as a whole and its subordinate factors were reliable in terms of internal consistency and stability.

\section{Validity}

Content validity was ensured by examining face content validity and quantitative content validity at different stages of the scale drafting process. The NPRS-HTPL items were based on the needs of pregnant women with TPL, identified from their maternity diaries, together with nurses' views of the care necessary for pregnant women with TPL, identified from a review of the literature on care for hospitalized pregnant women with TPL. The NPRS-HTPL was therefore considered useful as a method of assessing care to satisfy the needs of pregnant women with TPL. Criterion-related validity was confirmed on the basis of the significant correlation between the NPRS-HTPL and existing scales, the ASN and the QNCQ. In examining construct validity, participants were divided and compared by years of experience using the known-group method, showing significant differences between entry level and both senior mid-level nurses and veteran nurses, which were meaningful results. In a confirmatory factor analysis, a covariance structure analysis was used to examine a hypothetical model obtained from the exploratory factor analysis. Goodness-of-fit indices (GFI, CFI, and AGFI) with the five factors as the latent variables were all close to a value of 1 and met the criterion that GFI should be at least equal to AGFI. Values for RMR and RMSEA were both close to 0, and the RMSEA had a high

\begin{tabular}{|c|c|c|c|}
\hline Scales & Group & $\begin{array}{l}\text { Mean } \\
\text { (standard deviation) }\end{array}$ & Significant difference \\
\hline \multirow[t]{4}{*}{ Care That Enhances Self-Care Ability } & Entry level & $38.75(8.46)$ & Entry level $<$ Senior mid-level ${ }^{*}$ \\
\hline & Junior mid-level & $40.02(8.11)$ & Entry level $<$ Veteran nurses ${ }^{*}$ \\
\hline & Senior mid-level & $42.07(8.52)$ & \\
\hline & Veteran nurses & $42.49(9.60)$ & \\
\hline \multirow[t]{4}{*}{ Care that Changes Depending on the Situation } & Entry level & $27.62(4.96)$ & Entry level $<$ Senior mid-level ${ }^{*}$ \\
\hline & Junior mid-level & $28.43(3.96)$ & Entry level $<$ Veteran nurses ${ }^{*}$ \\
\hline & Senior mid-level & $28.74(4.03)$ & \\
\hline & Veteran nurses & $29.02(5.45)$ & \\
\hline \multirow{4}{*}{$\begin{array}{l}\text { Care that Respects the Wishes of Pregnant Women With } \\
\text { Threatened Preterm Labor }\end{array}$} & Entry level & $34.10(5.84)$ & Entry level $<$ Senior mid-level ${ }^{*}$ \\
\hline & Junior mid-level & $35.04(4.75)$ & \\
\hline & Senior mid-level & $35.87(4.89$ & \\
\hline & Veteran nurses & $36.18(5.31)$ & \\
\hline \multirow{4}{*}{$\begin{array}{l}\text { Care Related to Information to Predict the Future Lives of Pregnant } \\
\text { Women With Threatened Preterm Labor }\end{array}$} & Entry level & $29.00(5.39)$ & Entry level $<$ Senior mid-level ${ }^{*}$ \\
\hline & Junior mid-level & $30.20(4.62)$ & Entry level $<$ Veteran nurses ${ }^{*}$ \\
\hline & Senior mid-level & $30.79(4.65)$ & \\
\hline & Veteran nurses & $31.28(5.55)$ & \\
\hline \multirow[t]{4}{*}{ Practical Care for Continued Pregnancy } & Entry level & $28.35(4.99)$ & Entry level $<$ Senior mid-level ${ }^{*}$ \\
\hline & Junior mid-level & $29.52(4.29)$ & \\
\hline & Senior mid-level & $30.53(4.89)$ & \\
\hline & Veteran nurses & $29.61(5.02)$ & \\
\hline
\end{tabular}

Table 4: Comparison of the Nursing Practice Rating Scale for Hospitalized Pregnant Women with TPL(NPRS-HTPL) and by nurses' years of clinical experience. 
goodness-of-fit given a value of 0.08 or less, meaning that it met the criterion for adoption. A valid path coefficient of at least 0.5 was obtained between latent variables and observed variables in all question items. These findings indicated that the hypothetical model fitted well.

\section{The significance of factors identified in the NPRS-HTPL}

Factor 1 was Care That Enhances Self-Care Ability, which included items about facilitating pregnant women with TPL to be comfortable in hospital, while maintaining good relationships with their partner, family, and others. Factor 1 had a contribution ratio of about $40 \%$. This indicated that approximately $40 \%$ of care components for pregnant women with TPL corresponded to enhancing self-care ability. Manabe, Matsuda, Yoshinaga, Seto, and Agari [24] stated that self-care during pregnancy is essential in preparing for a maternal role and providing childcare. Self-care for pregnant women has also been presented as a specific nursing practice [25]. However, there was so study on behavior related to self-care of pregnant women who need medical care, such as pregnant women with TPL [26]. In the present study, nurses need to focus on supporting self-care in pregnant women with TPL, even if they are in a stable condition.

Care for pregnant women with TPL in Japan is usually centered on physical rest and drug therapy to support continuing pregnancy. These aspects of care respond flexibly to the symptoms of pregnant women with TPL and must be prioritized over everything else, depending on the condition of the pregnant women with TPL. In the scale, Factor 2, Care That Changes Depending on the Situation, and Factor 5, Practical Care for Continued Pregnancy, include care provided by nurses intended to avoid the risk of premature labor and ensure the safety of pregnant women with TPL. These factors also guarantee care for the purpose of continued pregnancy in pregnant women with TPL.

Factor 3, Care That Respects the Wishes of Pregnant Women With TPL, and Factor 4, Care Related to Information to Predict the Future Lives of Pregnant Women With TPL, involve the facilitation of relationships with the partner and family by nurses while respecting the position of the pregnant women with TPL. Because pregnant women with TPL receive more treatment and care than other pregnant women, many pregnant women with TPL experience a sense of loss of control, based on the feeling that they are entrusting the entire course of their pregnancy to medical professionals [13]. Factors 3 and 4 , therefore, represent care that leads to solutions to typical problems among these women.

Items concerning preparation for becoming a mother $(16,17,35$, 37-39) were also extracted. Terazono and Yamaguchi [27] stated that awareness of the role [28], acceptance and value of the role, and education on changes to the mother's social life that will occur as a result are important elements in developing the maternal role. These are all consistent with items in this study. It is critical for a pregnant woman living with a disorder such as TPL, and in an unfamiliar culture and environment, to be able to prepare for parenthood suitably, particularly to nurture maternal instincts, and to generate the energy required to care for a new baby [29]. For pregnant women at risk of TPL, as well as others, the NPRS-HTPL clarified the necessity of care to support this role development, as well as care to ensure physical safety and the continuation of pregnancy.
This scale includes items about promoting self-care in pregnant women with TPL, solving typical problems of pregnant women with TPL, and promoting the acquisition of a maternal role. There is criterion-related validity between the scale of Horiuchi et al. [22] and this scale, suggesting that this scale is suitable for evaluating the quality of care for pregnant women with TPL.

\section{Limitations}

In the NPRS-HTPL development process, items with strong bias at the item analysis and factor analysis stages and items with weak factor loadings were removed, despite the fact that they included important care categories. While this is an unavoidable aspect of scale development, there were problems with the expression of some question items. The NPRS-HTPL could, however, indicate care that allows women to spend their time in hospital meaningfully, as part of treatment to pursue optimal delivery and prevent preterm labor, without any serious after-effects during the delivery period. Finally, this scale focuses on care for pregnant women with TPL receiving LTTT, so it is not suitable for use with women in acute preterm labor.

\section{Conclusions}

The NPRS-HTPL had acceptable reliability and validity among pregnant women hospitalized for TPL in Japan. Important items for the improvement of self-care ability and promotion of maternal role acquisition were extracted, and the criterion-related validity of items in the improvement of care quality was ensured. The reliability of the NPRS-HTPL was supported. The scale might be a useful tool with which to evaluate nursing practice to support pregnant women with threatened preterm labor while they are in hospital.

By conducting self-evaluations using this scale, nurses involved in the care of pregnant women with TPL could become more aware of the level of care they are providing to these women and objectively review their own care practices. This scale is therefore expected to be useful as a tool to improve care through self-evaluation. Examinations focusing on each of the five factors could serve as indices for teams, as well as pregnant women with TPL and nurses, to continue toward the same goal and share results at team conferences and other meetings. The NPRS-HTPL could also act as a guideline for nurses with different clinical experience, positions, and occupations to provide high-quality care, without causing discomfort to pregnant women with TPL as a result of differences in care provision between nurses.

\section{Competing Interests}

The author declears that they have no competing interest exists.

\section{References}

1. Tanaka K, Yamamoto YF, Futagami M, Fukui A, Ozaki T, Mizunuma H (2004) Discussion from literature about the diagnosis and treatment of preterm labor and preterm birth. Journal of The Aomori Society of Obstetricians and Gynecologists 19: 91-36.

2. Nakai A (2009) Sepakusouzan no soukihaken to tiryou. Perinatal Medicine 39: $1323-1329$

3. Baumgarten K, Gruber W (1974) Tokolyseindex. In J. W. Dudenhause \& E. Saling (Eds.). Perinatale Medizin (pp. 58-59).

4. Masaoka N, Morooka M (2011) Hospitalization in preterm labor hospital management and care. Perinatal Care 30: 120-123. 
Citation: Yamamoto H, Oike M (2017) Development of a Nursing Practice Rating Scale for Hospitalized Pregnant Women with Threatened Preterm Labor. Int J Nurs Clin Pract 4: 265. doi: https://doi.org/10.15344/2394-4978/2017/265

5. Shiozaki A, Saitoh S (2008) Managements of threatened premature delivery. Obstetrical and Gynecological Therapy 96: 128-133.

6. Kamiya K (2015) Maternal and Child Health Statistics of Japan. Japan: Mothers' \& Children's Health Organization.

7. Kawagoe $\mathrm{Y}$, Sameshima $\mathrm{H}$ (2009) Tocolytic therapy for preterm labor Obstetrical and Gynecological Therapy 98: 347-352.

8. Sprague AE (2004) The evolution of bed rest as a clinical intervention. Journal of Obstetric Gynecologic \& Neonatal Nursing 33: 542-549.

9. American College of Obstetrics and Gynecologists committee. (2006). Innovative practice: ethical guidelines. Committee opinion 352: 1-7.

10. Maloni JA, Park S (2005) Postpartum symptoms after antepartum bed rest Journal of Obstetric, Gynecologic, and Neonatal Nursing: JOGNN 34: 163171

11. Matsuura S, Yoshizawa T (2011) Psychological states of pregnant women required to undergo bed rest. Japan Society of Maternal Health, 51: 647654.

12. Nakamura $Y$, Atogami $F$, Takeuchi $M$, Yoshizawa $T$ (2012) Attitude toward their pregnancy of hospitalized pregnant women in threatened premature labor in Japan. Japan Journal of Maternal Health 53: 313-321.

13. Saeki A, Mori E, Reiko S (2003) Pregnant women's acceptance process of situational change according to symptom of preterm birth and nursing care. Journal of Chiba Academy of Nursing Science 9: 35-41.

14. Imamura A, Nakamura Y, Atogami T, Yoshizawa T (2013) Positive experiences of hospitalized pregnant women in TPL in Japan. Japanese Journal of Maternal Health 54: 22-25.

15. Toyota K, Kishiyama N, Nakamura A, Suizu E, Matsumoto Y (2015) Nyuinchu no seppakusouzanninpu ni jissisita kouryuukai no huan sutoresukeigen no kouka. Nihon kango gakkai ronbunsyu 45: 113-116.

16. Usami T, Sasaki A, Onodera M, Anno T, Tamasaki Y, et al. (2013) Neuinsiteiru seppakusouzannninpu no kouteitekinataiken ni tuite. Nihon kango gakkai ronbunsyu 43: 22-25.

17. Kodama K (2015)Thoughts expressed in a "maternity diary" by pregnant women with threatened delivery hospitalized at the maternal and fetal intensive care unit. Journal of Japan Red Cross Society Nursing Science 15: $21-29$.

18. Kobayashi H, Nakaya T, Moriyama M (2012) Development of an anticipatory grief scale for family caregivers of a person dying at home. Journal of Japan Academy of Nursing Science 32: 41-51.

19. Yoshioka S (2009) Development of "MITORI" Care Scale to evaluate nursing care for patients with end-stage cancer and their families. Journal of Japan Academy of Nursing Science 29: 11-20.

20. Igawa $Y$ (2013) Examination of reliability and validity of the NURSERV-J for evaluation of the quality of the nursing service in an acute care hospital. Journal of Japan Academy of Nursing Science 33: 56-65.

21. Kikuchi A, Harada T (1997) A study on the measurement of professional autonomy in nursing. Shizuoka University Repository 47: 241-254.

22. Horiuchi S, Ota K, Kayama M, Mori A, Komatsu H, et al. (1996) Development of questionnaire to measure the quality of nursing care for patients and nurses. Journal of Japan Academy of Nursing Science 16: 30-39.

23. Oshio S (2004) Covariance structure analysis. In Psychological and survey data analysis by SPSS and Amos (pp. 180-183). Tokyo: Tokyo-tosho

24. Manabe E, Matsuda K, Yoshinaga K, Seto M, Agari I (2006) Effect of selfcare behavior by primiparae during pregnancy on delivery and sense of achieving a maternal role. Japan Journal of Maternal Health 47: 421-428.

25. Lowdermilk D, Perry S (2006) Unit Two: Pregnancy. In Maternity Nursing (7th ed.) (pp. 253-271). U.S.A.: Mosby.

26. Hawkins J, Aber C, Cannan A, Coppinger C, Rafferty K (1998) Women's reported self-care behaviors during pregnancy. Health Care for Women International 19: 529-538.

27. Terazono S, Yamaguchi K (2015) Development of the scale for mother's roles in the childcare period. The Journal of Child Health 4: 491-497.
28. Maehara K, Mori E (2005) Development of the Postpartum Maternal Confidence Scale and the Postpartum Maternal Satisfaction Scale. Journal of Graduate School of Nursing, Chiba University 27: 9-18.

29. Shimada K (2011) Mother's class power up guide. The Japanese Journal of Perinatal Care (pp19). Tokyo: Medica Publication. 